\title{
Impact of Energy Storage System Response Speed on Enhanced Frequency Response Services
}

DOI:

10.1109/ECCE.2019.8912725

\section{Document Version}

Other version

Link to publication record in Manchester Research Explorer

\section{Citation for published version (APA):}

Zhu, Q., Bolzoni, A., Forsyth, A., \& Todd, R. (2019). Impact of Energy Storage System Response Speed on

Enhanced Frequency Response Services: 2019 IEEE Energy Conversion Congress and Exposition (ECCE). 25232529. Paper presented at 2019 IEEE Energy Conversion Congress and Exposition (ECCE), Baltimore, MD, United States. https://doi.org/10.1109/ECCE.2019.8912725

\section{Citing this paper}

Please note that where the full-text provided on Manchester Research Explorer is the Author Accepted Manuscript or Proof version this may differ from the final Published version. If citing, it is advised that you check and use the publisher's definitive version.

\section{General rights}

Copyright and moral rights for the publications made accessible in the Research Explorer are retained by the authors and/or other copyright owners and it is a condition of accessing publications that users recognise and abide by the legal requirements associated with these rights.

\section{Takedown policy}

If you believe that this document breaches copyright please refer to the University of Manchester's Takedown Procedures [http://man.ac.uk/04Y6Bo] or contact uml.scholarlycommunications@manchester.ac.uk providing relevant details, so we can investigate your claim.

\section{OPEN ACCESS}


This paper was published at the IEEE Energy Congress and Exposition (ECCE) in Oct. 2019, DOI 10.1109/ECCE.2019.8912725, and is available at:

https://ieeexplore.ieee.org/stamp/stamp.jsp?tp=\&arnumber=8912725

Q. Zhu, A. Bolzoni, A. Forsyth and R. Todd, "Impact of Energy Storage System Response Speed on Enhanced Frequency Response Services," IEEE Energy Conversion Congress and Exposition (ECCE), 2019, pp. 2523-2529, DOI: 10.1109/ECCE.2019.8912725.

(C) 2019 IEEE. Personal use of this material is permitted. Permission from the IEEE must be obtained for all other uses, in any current or future media, including reprinting/republishing this material for advertising or promotional purposes, creating new collective works, for resale or redistribution to servers or lists, or reuse of any copyrighted component of this work in other works. 


\title{
Impact of Energy Storage System Response Speed on Enhanced Frequency Response Services
}

\author{
Qingwei Zhu, Alberto Bolzoni, Andrew Forsyth, and Rebecca Todd \\ School of Electrical and Electronic Engineering, \\ The University of Manchester \\ Manchester, United Kingdom \\ qingwei.zhu@manchester.ac.uk, andrew.forsyth@manchester.ac.uk
}

\begin{abstract}
This paper investigates the impact of energy storage systems (ESSs) response speed on its ability to perform fast frequency support services such as the UK's enhanced frequency response (EFR) services. The response time of a commercial Siemens SieStorage 240kVA/180kWh grid-linked battery energy storage system (BESS) is characterized and the results are used to model an emulated BESS in a representative micro-grid system using a real-time digital simulator (RTDS). The SieStorage system is also linked to the RTDS micro-grid through an Ethernet connection, forming a hardware-in-theloop (HIL) system. Simulations and then HIL tests of the emulated BESS providing EFR to the micro-grid are conducted to investigate the impact of the communication latency, the physical power delivery time, and also the installed capacity of the BESS. The study shows that the communication latency has a much more significant impact than the physical power delivery time; for better EFR support, reducing the communication latency of a BESS could be even more effective than increasing the power capacity, which is costly.
\end{abstract}

Keywords- Battery, energy storage system, enhanced frequency response, hardware-in-the-loop, response time

\section{INTRODUCTION}

Driven by decarbonisation, the power networks in many countries worldwide are seeing a rapid increase in powerelectronic-connected renewable generators [1-4] such as wind farms and photovoltaic plants, at both the transmission and distribution network level. However, the ever increasing penetration of these generators will lead to a more variable, less predictable grid system [5]. This is likely to increase the regularity and severity of frequency events [6] in future power systems and raises greater challenges for grid operators. Meanwhile, diverse energy storage systems (ESSs) including hydro, thermal, compressed-air, flywheel, battery, superconducting-magnetic systems, are being investigated as possible solutions to tackle the new challenges facing the grid. Amongst these different ESSs, battery storage [2, 7-10] is one type attracting particular interest due to its relatively high efficiency [9] and fast response speed.

Today, modern power systems such as those in the UK, Germany and Sweden [1] are embracing ESSs mainly for frequency regulation. In addition to the existing services like the short term operating reserve (STOR) and firm frequency response (FFR), the UK National Grid Electricity Transmission (NGET) network operator, operates a new faster frequency response service, called enhanced frequency response (EFR), to provide a fast response to support the grid

This work was supported by the UK Engineering and Physical Sciences Research Council (EPSRC) under the Multi-scale ANalysis for Facilities for Energy STorage (Manifest) project [EP/N032888/1] in times of low system inertia [3, 11]. There are two EFR service options, the wide band service (service1), which requires the ESS to respond when the frequency is outside of the range $49.95-50.05 \mathrm{~Hz}$, and the narrow band service (service2), where the dead-band is $49.985-50.015 \mathrm{~Hz}$. For both, NGET requires a response within one second and the capability to provide more than $1 \mathrm{MW}$, either as a single site or as an aggregated ESS fleet. The first round of EFR tendering resulted in eight awards, totalling to 201MW, and all are battery energy storage system (BESS).

The majority of the published work on BESS, and especially that considering EFR is focused on state-of-charge (SoC) management $[2,7,8,12]$ with the exception of [6] which considered the BESS response time of $80 \mathrm{~ms}$, however this was an emulated system. In this paper, the impact of the BESS maximum power, and response speed on its ability to deliver EFR services is investigated. Firstly, a characterisation study on the response time of a commercial Siemens SieStorage 240kVA/180kWh BESS is carried out. Using the characterisation results an emulated BESS is modelled within a representative micro-grid system through a power system real-time digital simulator (RTDS). Comprehensive simulations are then undertaken to look at the impacts of the communication latency, delivery time, as well as the power capacity of the BESS on its ability to provide EFR to support the micro-grid. Both the wide band and narrow band EFR services are studied. Moreover, hardware-in-the-loop (HIL) tests with the SieStorage system linked to the RTDS micro-grid model are conducted to validate the simulation.

\section{RESPONSE TIME CHARACTERASATION OF A COMMERTIAL BATTERY ENERGY STORAGE SYSTEM}

\section{A. System description}

The battery energy storage system studied is a Siemens SieStorage, shown in Figure 1. The nominal power/energy capacity of the SieStorage is $240 \mathrm{kVA} / 180 \mathrm{kWh}$. The battery comprises four racks, each consist of fourteen $48 \mathrm{~V}$ lithiumion polymer UPB4860 modules manufactured by LG Chem. The system is connected to the local low-voltage distribution grid via a $260 \mathrm{kVA}, 400 / 433 \mathrm{~V}$ transformer. The system has a three-level hierarchical control architecture as shown in Figure 2. The lowest accessible level of control is the programmable logic controller (PLC), which directly interfaces with the battery management system, the protection relays, the circuit breakers, the cycle-to-cycle controller for the power converters, and all other subsystems within SieStorage. The PLC communicates with a dSPACE 
real-time platform (DS1007) through a Profibus connection. The dSPACE platform is the central controller of SieStorage, and it is interfaced using TCP/IP Ethernet to the RTDS, which in this study is used to represent a remote controller like an ESS aggregator or grid transmission system operator (TSO).

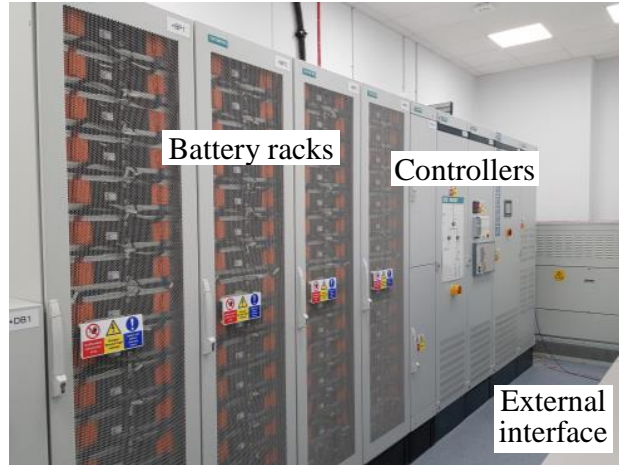

Figure 1. SieStorage battery energy storage system.

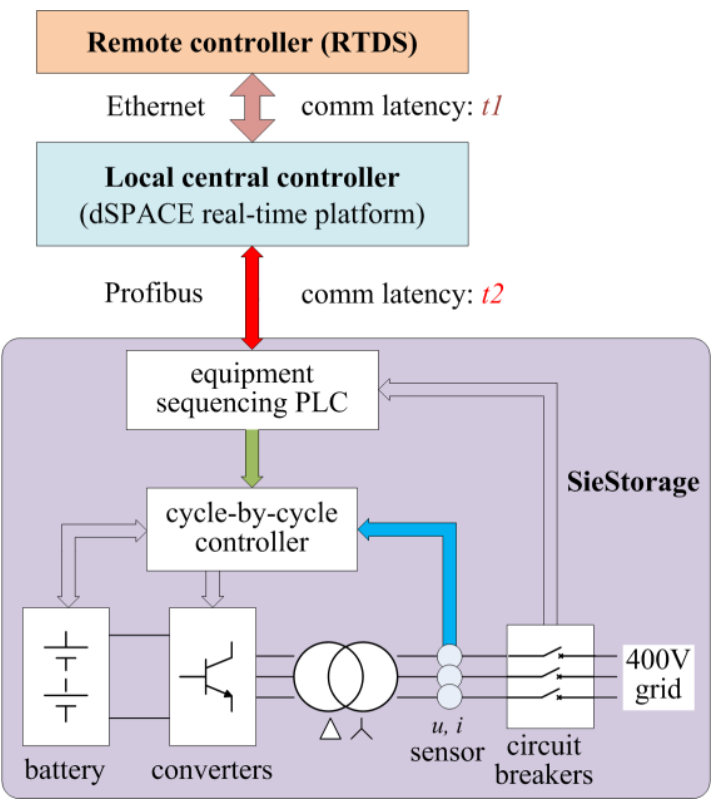

Figure 2. Diagram of the three-level control structure of SieStorage.

\section{B. Response Time Characterisation Tests}

The response time of SieStorage, from when a setpoint is sent from the remote controller (RTDS) to when the remote controller receives measured data showing delivery of the setpoint, has been characterized through a series of step power tests and a set of continuous power tests. The step tests cover three different levels of power, $80 \mathrm{~kW}, 160 \mathrm{~kW}$, and $240 \mathrm{~kW}$, and four different SoC levels, 25\%, 45\%, 65\%, and $85 \%$. As an example, Figure 3(a) shows the power profile from the $240 \mathrm{~kW}$ step test with a battery SoC of $65 \%$. The continuous power tests include six ramp tests with different ramp rates, $\pm 60 \mathrm{~kW} / \mathrm{s}, \pm 120 \mathrm{~kW} / \mathrm{s}, \pm 240 \mathrm{~kW} / \mathrm{s}$, (the $+60 \mathrm{~kW} / \mathrm{s}$ case is shown in Figure 3(b)), and two arbitrary real power tests resembling an over-frequency EFR event and a down-frequency EFR event, which is shown in Figure $3(\mathrm{c})$. The communication latencies $t 1, t 2$ between the controllers shown in Figure 2, the grid-side line current transient time $t_{\text {tran }}$, the physical execution time $t_{\text {excu }}$, and the total response time $t_{\text {resp }}$, of SieStorage are all investigated.
The plots in Figure 3 show four waveforms captured in the RTDS, the setpoint from the RTDS simulator 'RTDS to dSPACE', the setpoint that dSPACE received from RTDS and passes to SieStorage 'dSPACE to SieS', the SieStorage accepted value 'SieS accepted', and the SieStorage output power measurement 'SieS measured'. A Yokogawa PX8000 power analyser was used to measure the grid-side, threephase, line-to-line voltages and line currents to obtain the instantaneous power 'Actual measured'.

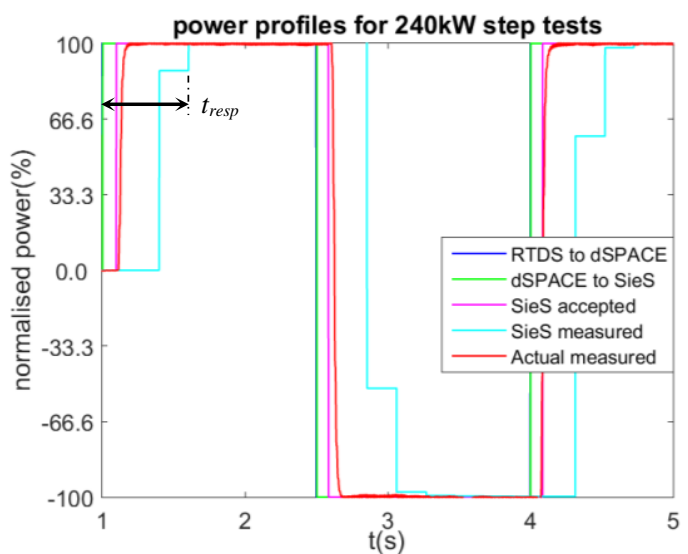

(a)

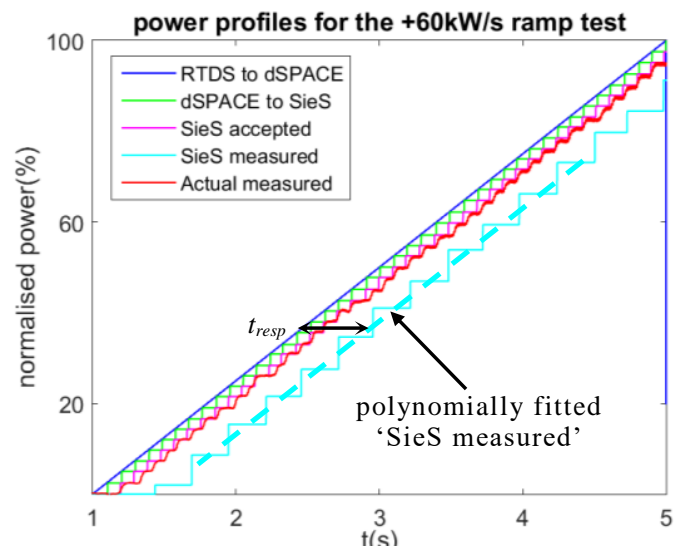

(b)

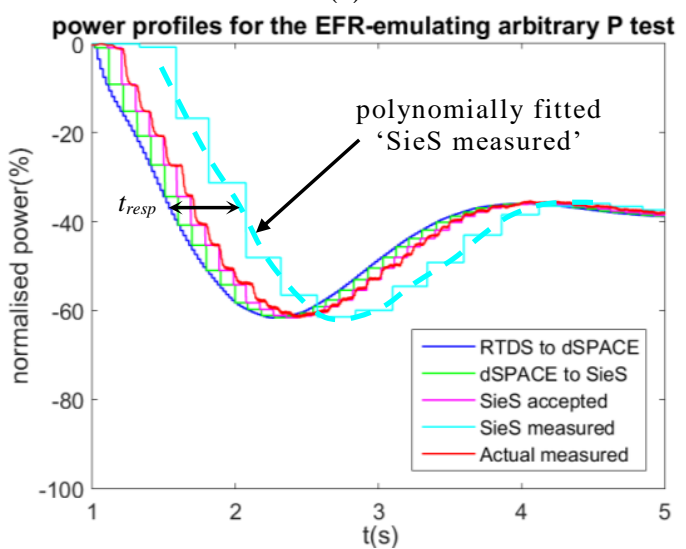

(c)

Figure 3: Measured power profile samples of the characterization tests, (a) step tests at the power level of $240 \mathrm{~kW}$ and SoC of $65 \%$, (b) $+60 \mathrm{~kW} / \mathrm{s} \mathrm{ramp}$ test, (c) down-frequency EFR-emulating arbitrary real power test.

In Figure 3 the main latencies are between 'dSPACE to SieS' and 'SieS accepted', and between 'SieS accepted' and 'SieS measured'. To investigate this further, the known, measurable communication latencies are sketched in Figure 4 , showing the control and response sequences of SieStorage. 
In Figure $4, t_{\text {delay }}$ is the time after subtracting $t 1, t 2$, and $t_{\text {tran }}$ from $t_{\text {excu }}$, representing the time delay from the cycle-to-cycle controller of the power converter to the PLC. $t_{\text {delay }}$ and $t_{\text {tran }}$ are merged to form $T_{d l v}$, to represent the total delivery time of the SieStorage power converter. And $t 1$ and $t 2$ are combined to form $T_{\text {comm }}$, to represent the total communication delay of SieStorage to receive commands from a remote controller.

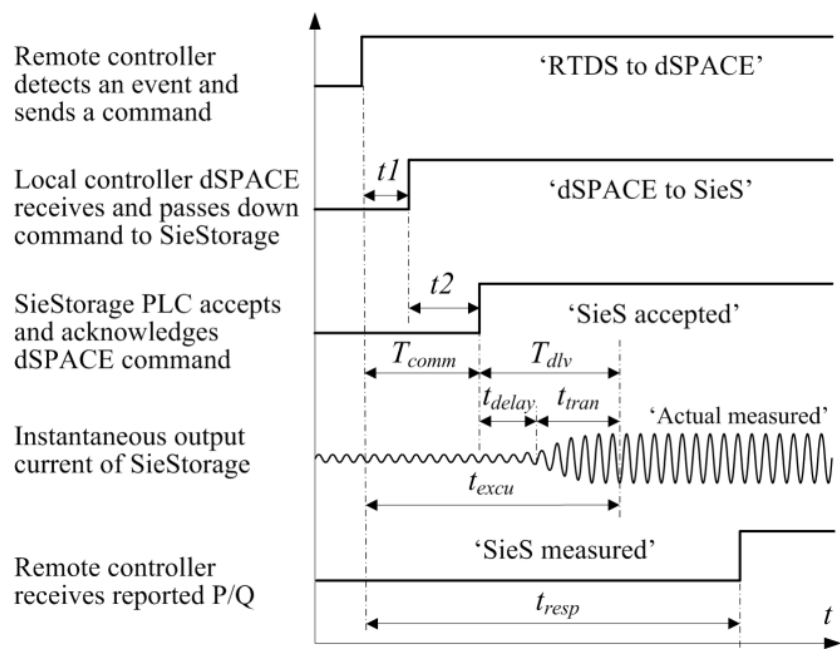

Figure 4. Control and response sequences of SieStorage.

$t 1$ and $t 2$ are then estimated according to Figure 4 by comparing the 'dSPACE to SieS' signal, the 'SieS accepted' signal to the initiating signal 'RTDS to dSPACE', respectively. $t_{t r a n}$ is only investigated in the step tests, by identifying the $2 \%$, and the $98 \%$ values of the line current to determine the physical start time and fulfilment time for each command; then $t_{\text {tran }}$ and $t_{\text {excu }}$ is evaluated. For the step test, $t_{\text {resp }}$ is estimated by identifying the moment of when the new setpoint is reached on the 'SieS measured' signal, which is indicated with the arrow in Figure 3(a).

For the continuous tests, the measured instantaneous power curve 'Actual measured' is polynomially fitted, and $t_{\text {excu }}$ is estimated by comparing this poly-fitted curve to the original 'RTDS to dSPACE' signal. The power curve 'SieS measured' is also polynomially fitted as shown in Figure 3(b) and Figure 3(c), to calculate the averaged $t_{\text {resp }}$.

\section{Results}

The detailed characterisation results of SieStorage's response time are summarised in Table I. The remote-tolocal communication latency $t 1$ (between 'RTDS to dSPACE' and 'dSPACE to SieS') is approximately $4 \mathrm{~ms}$, while the communication latency $t 2$ (between 'dSPACE to SieS' and 'SieS accepted') is an average of $86 \mathrm{~ms}$, due to the loop-back acknowledgement algorithm [13] implemented in the dSPACE controller of the SieStorage system.

TABLE I. RESPONSE TIME CHARACTERISATION RESULTS

\begin{tabular}{|c|c|c|c|c|c|c|c|c|c|c|c|}
\hline \multirow{2}{*}{ test } & \multicolumn{3}{|l|}{ step tests $(\mathbf{k W})$} & \multicolumn{6}{|c|}{ Ramp tests (kW/s) } & \multicolumn{2}{c|}{ EFR tests } \\
\cline { 2 - 12 } & $\mathbf{8 0}$ & $\mathbf{1 6 0}$ & $\mathbf{2 4 0}$ & $\mathbf{6 0}$ & $\mathbf{- 6 0}$ & $\mathbf{1 2 0}$ & $\mathbf{- 1 2 0}$ & $\mathbf{2 4 0}$ & $\mathbf{- 2 4 0}$ & $\boldsymbol{E F R 1}$ & $\boldsymbol{E F R 2}$ \\
\hline$t 1(\mathrm{~ms})$ & 5.0 & 3.0 & 3.1 & 4.3 & 5.1 & 4.5 & 4.5 & 5.4 & 5.2 & 2.8 & 3.1 \\
\hline$t 2(\mathrm{~ms})$ & 84 & 86 & 90 & 87 & 84 & 86 & 87 & 84 & 87 & 84 & 86 \\
\hline$t_{\text {excu }}(\mathrm{ms})$ & 143 & 158 & 167 & 157 & 154 & 181 & 177 & 160 & 167 & 156 & 150 \\
\hline$t_{\text {resp }}(\mathrm{ms})$ & 570 & 582 & 653 & 478 & 477 & 477 & 480 & 497 & 477 & 469 & 465 \\
\hline
\end{tabular}

$t_{\text {tran }}$ indicates the response time of the power converter, and $t_{\text {excu }}$ represents the actual performance of the BESS from the change in set-point to SieStorage delivering the new setpoint. Step test results of $t_{\text {tran }}$ and $t_{\text {excu }}$ are shown in Figure 5. Both $t_{\text {tran }}$ and $t_{\text {excu }}$ increases approximately linearly with power level, but are not significantly affected by the SoC of the battery. The average $t_{\text {tran }}$ for delivering full real power from zero is around $45 \mathrm{~ms}$. $t_{\text {tran }}$ for a power reversal command from full charge/discharge to full discharge/charge, takes $56 \mathrm{~ms}$ on average. All these transient times are within three utility cycles, indicating the high performance of the power converter of this commercial BESS.

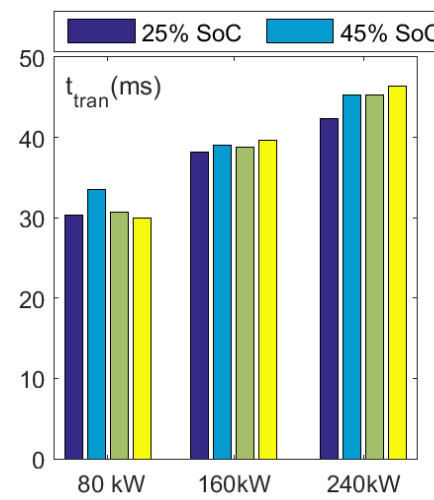

(a)

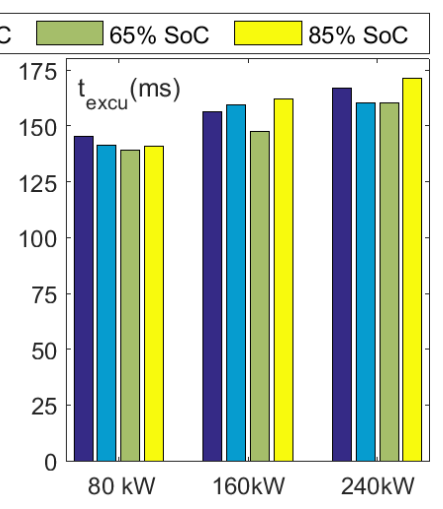

(b)
Figure 5: Response times of SieStorage system. (a) $t_{\text {tran }}$, (b) $t_{\text {excu }}$.

$t_{\text {exси }}$ has negligible dependence on power, or SoC, and is an average $162 \mathrm{~ms}$. $t_{\text {exс }}$ shows the time from the remote controller RTDS commanding a setpoint change, to SieStorage delivering the new response, however RTDS does not know the change in SieStorage output until $t_{\text {resp }}$.

$t_{r e s p}$ was measured to be in the range of $465-497 \mathrm{~ms}$ with a high consistency in the continuous tests, and the average value of $t_{\text {resp }}$ is $477 \mathrm{~ms}$; while the value of $t_{\text {resp }}$ estimated from the step tests is $602 \mathrm{~ms}$ on average. The difference of $125 \mathrm{~ms}$ between them is approximately half of the SieStorage system's measurement sampling time (around 260ms measured), which is due to the polynomial fitting process for $t_{\text {resp }}$ evaluation of the continuous tests as shown in Figure 3(b) and Figure 3(c). However, continuous power operation rather than delivering abrupt large power steps is how a BESS works in real application scenarios like providing EFR, therefore, $477 \mathrm{~ms}$ is taken as the total response time of SieStorage.

Figure 6 shows the breakdown of $t_{\text {excu }}$, and for SieStorage, $T_{\text {comm }}$ is the dominant portion (almost $56 \%$ ) of the total response time $t_{\text {excu. }}$. The following section investigates how $T_{d l v}$ and $T_{c o m m}$ of a BESS affect its ability to provide EFR services.

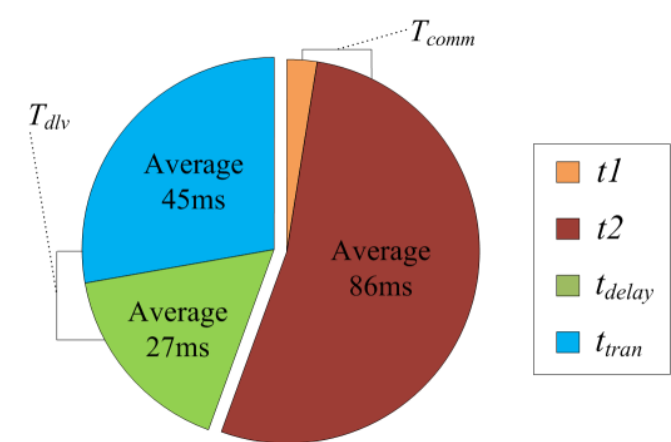

Figure 6. Breakdown of $t_{\text {excu }}$ of SieStorage. 


\section{SimUlation STUDY ON THE IMPACT OF RESPONSE TIME FOR ENHANCED FREQUECY RESPONSE SERVICES}

\section{A. RTDS Model Description}

A representative lumped micro-grid model (shown in Figure 7) consisting of a synchronous generator (SG), an emulated BESS, and dynamic loads is programmed in RTDS to enable quick evaluation of the impact of different response times and power ratings. The inertia constant of the 10MVA SG is set to $2.5 \mathrm{MJ} / \mathrm{MVA}$, which is consistent with the estimated overall inertia of the UK power system [5]. The emulated BESS in this study is modelled by a dynamic AC source from the RTDS component library, and its power capacity $P_{B E S S}$ is set to $0.5 \mathrm{MW}$. The dynamic characteristic of this AC source is set according to the characterisation results of the SieStorage system as described in the previous section.

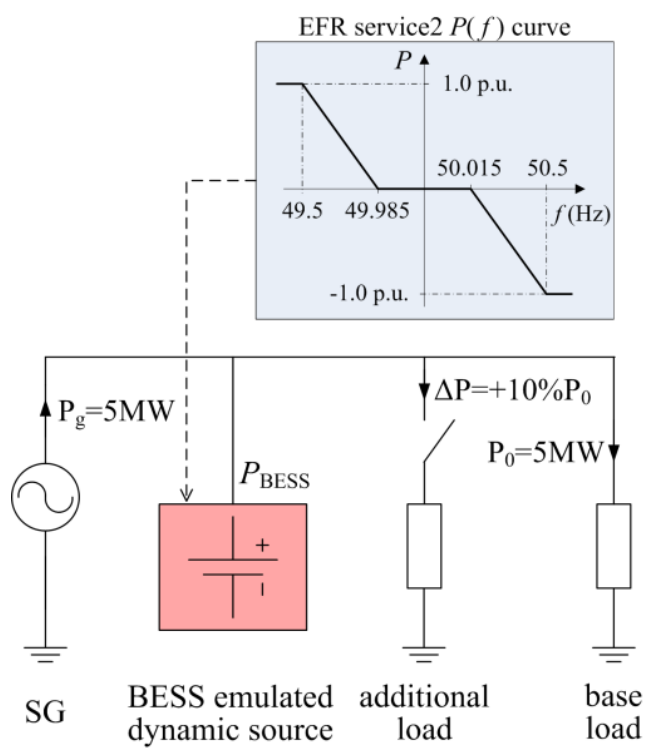

Figure 7: Diagram of the representative micro-grid system model.

\section{B. Simulation Study on the BESS Response Time}

A basic $10 \%$ load-generation imbalance event is studied to see how different response times of the emulated BESS affect its ability to provide EFR services to support the micro grid. The simulation scenario is described as follows, initially the system is operated in a load-generation balanced state of $5 \mathrm{MW}$, then at $\mathrm{t}=2 \mathrm{~s}$, a $0.5 \mathrm{MW}$ ( $10 \%$ of the base load) new load is added to the micro-grid system. This stepped load event automatically triggers the primary regulation of the SG and causes the frequency of the micro-grid system to deviate from the nominal value of $50 \mathrm{~Hz}$.

The resultant frequency drop, in particular the frequency nadir $\Delta f_{\max }$ (maximum frequency deviation), which occurs at the early stage of the primary control of the generator, is considered in this simulation study. $f$ profiles without and with the BESS providing EFR are compared. Both the wide band EFR service1 and narrow band EFR service2 are studied; and in the simulation, the EFR $P(f)$ curve [11] is defined by the EFR dead band frequencies $(49.985 \mathrm{~Hz}$ and $50.015 \mathrm{~Hz}$ for service 2 as shown in Figure 7) and the EFR threshold frequencies $(49.5 \mathrm{~Hz}$ and $50.5 \mathrm{~Hz})$. Due to the shortness of the EFR timescale, secondary regulation of the $\mathrm{SG}$ is not considered in this study. Five communication latency $T_{\text {comm }}$ settings, $0.01 \mathrm{~s}, 0.05 \mathrm{~s}, 0.1 \mathrm{~s}, 0.2 \mathrm{~s}$, and $0.5 \mathrm{~s}$, and five delivery time $T_{d l v}$ settings, $0.06 \mathrm{~s}, 0.1 \mathrm{~s}, 0.15 \mathrm{~s}, 0.2 \mathrm{~s}$, and
$0.3 \mathrm{~s}$, are compared. The impact of the installation capacity $P_{B E S S}$ of the emulated BESS is also investigated; four different power ratings, $0.25 \mathrm{MW}, 0.5 \mathrm{MW}, 0.75 \mathrm{MW}$, and 1.0 MW, are compared.

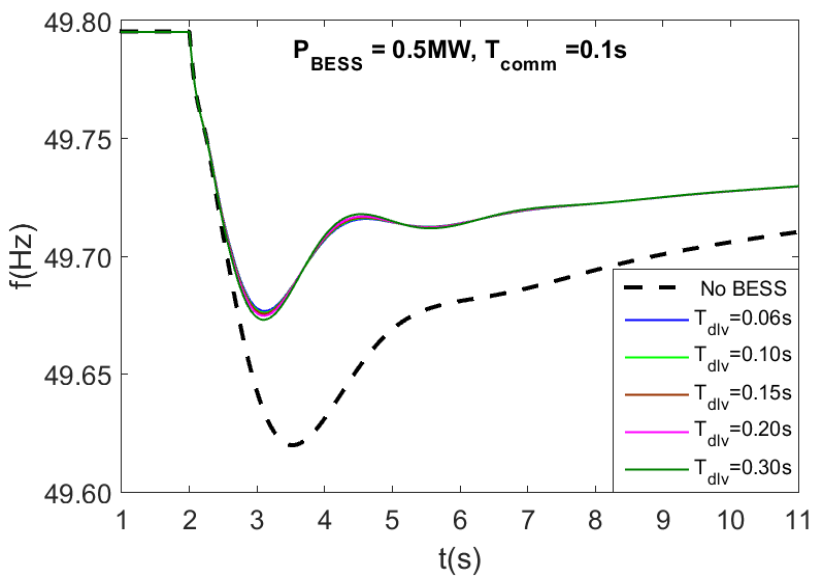

(a)

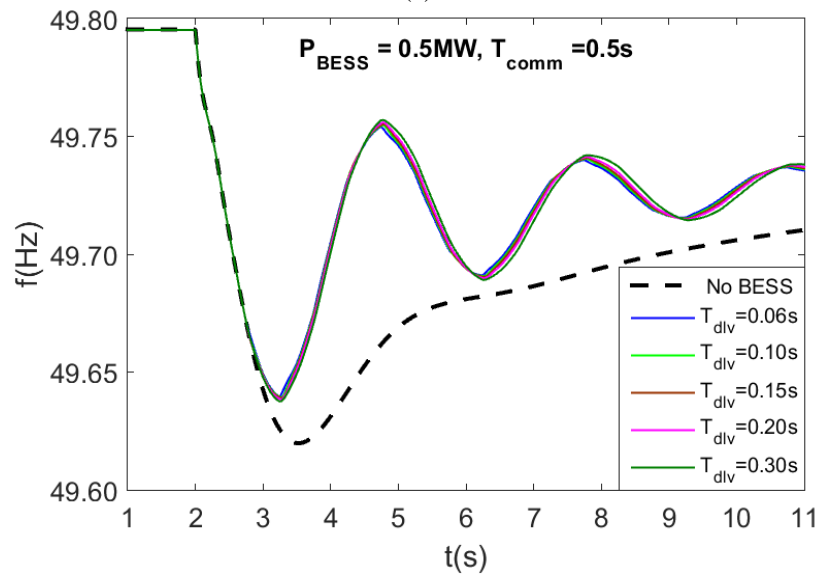

(b)

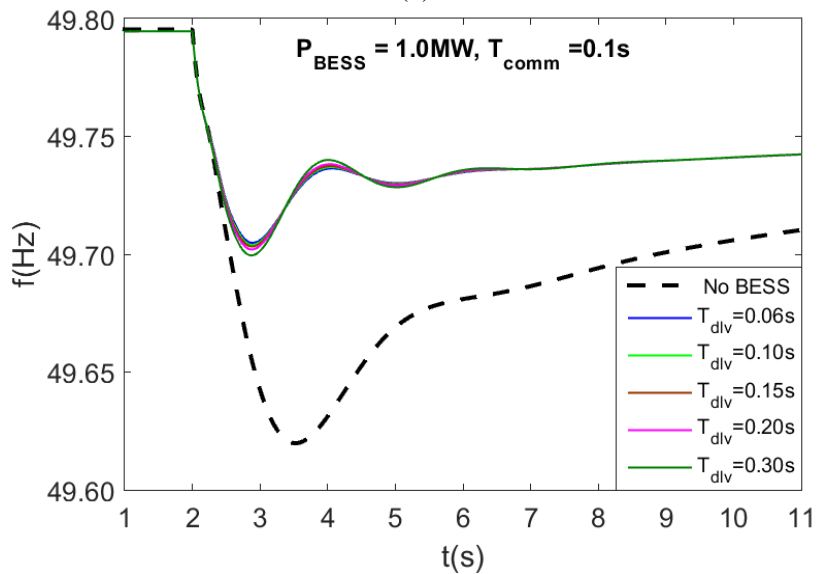

(c)

Figure 8. Sensitivity of the BESS's EFR performance to $T_{d l v}$, narrow band EFR service2. (a) $P_{B E S S}=0.5 \mathrm{MW}, T_{\text {comm }}=0.1 \mathrm{~s}$, (b) $P_{\text {BESS }}=0.5 \mathrm{MW}, T_{\text {comm }}=0.5 \mathrm{~s}$, (c) $P_{B E S S}=1.0 \mathrm{MW}, T_{\text {comm }}=0.1 \mathrm{~s}$.

\section{Simulation Results}

The sensitivity of the BESS power converter's delivery time $T_{d l v}$ on EFR performance is first investigated. The frequency transient profiles with the BESS having two different values of $T_{\text {comm }}, 0.1 \mathrm{~s}$ and $0.5 \mathrm{~s}$, and two different power capacities $P_{B E S S}, 0.5 \mathrm{MW}$ and $1 \mathrm{MW}$, are shown in 
Figure 8 for a range of values of $T_{d l v}$. The storage system was programmed to provide the narrow band EFR service2. For all three cases, the frequency nadir $\Delta f_{\max }$ is clearly reduced by the BESS. As expected, a higher capacity BESS can more effectively reduce the frequency nadir caused by the stepped load event, as shown by comparing Figure 8(a) and 8(c). Figure 8 also shows that the delivery time $T_{d l v}$ of the power converter of a BESS has little impact on its performance. Figure 8(b) shows that the large communication latency causes increased frequency oscillations and a prolonged frequency settling time to the micro-grid system, though the BESS does still mitigate the steady state frequency deviation.

The impact of $T_{\text {comm }}$ is further studied under different power capacities for a fixed $T_{d l v}$ of $0.1 \mathrm{~s}$ and the results are shown in Figure 9. Both plots in Figure 9 indicate that a longer $T_{\text {comm }}$ results in a greater frequency nadir. A longer $T_{\text {comm }}$ also causes larger oscillations and prolongs the frequency settling time. Figure 9(b) shows that if the BESS has a high capacity compared to the micro-grid, then a long $T_{\text {comm }}$ may even cause instability.

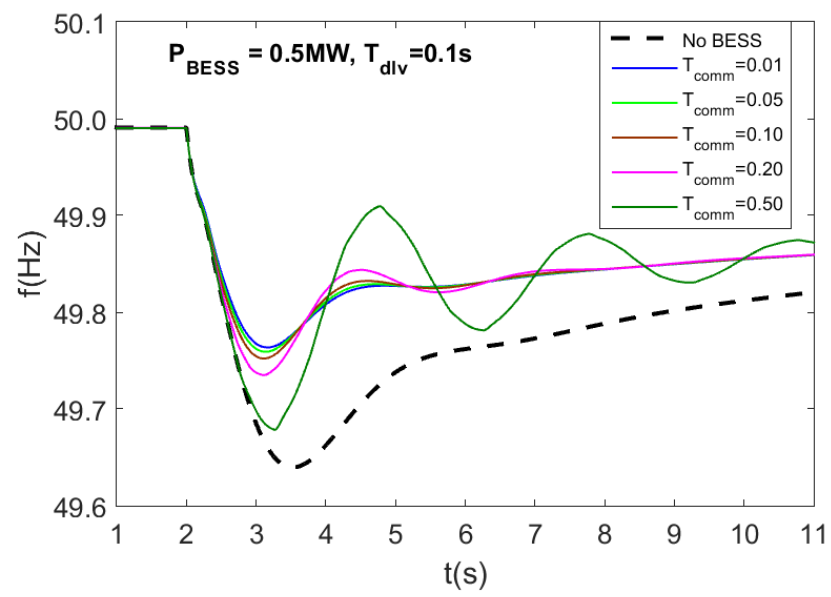

(a)

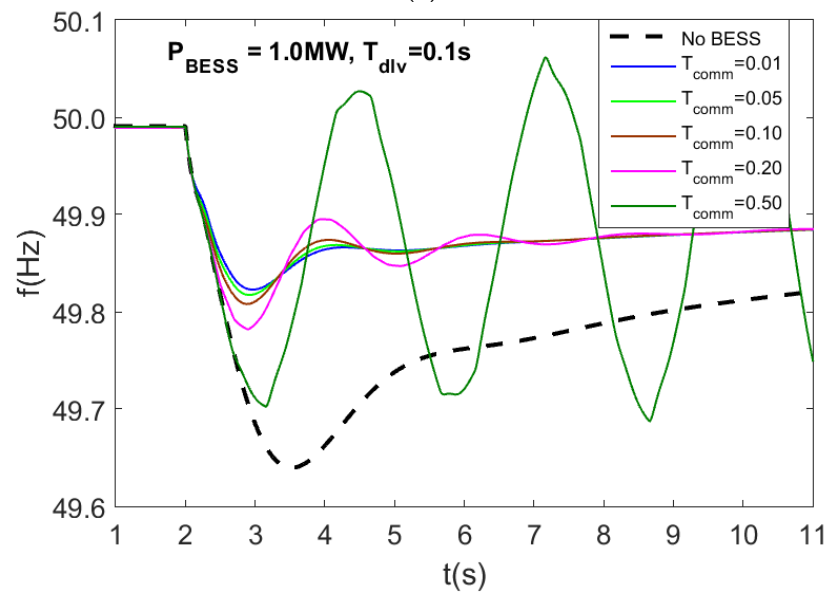

(b)

Figure 9. Sensitivity of the BESS's EFR performance to $T_{\text {comm }}$, narrow band EFR service 2 . (a) $P_{B E S S}=0.5 \mathrm{MW},(\mathrm{b}) P_{B E S S}=1.0 \mathrm{MW}$.

The frequency nadir $\Delta f_{\max }$ against $T_{\text {comm }}$ for the four different power capacities are shown in Figure 10, revealing the sensitivity of EFR performance to the installed power capacity of the frequency supporting BESS. As shown, $\Delta f_{\max }$ increases with $T_{\text {comm }}$, and decreases with $P_{B E S S}$ almost linearly. A $0.5 \mathrm{MW}$ BESS with communication latency less than $0.1 \mathrm{~s}$ would outperform a $1.0 \mathrm{MW}$ system which has communication latency slower than $0.32 \mathrm{~s}$. The cost of shortening the communication latency of a BESS from $0.32 \mathrm{~s}$ to $0.1 \mathrm{~s}$ will likely be much less than the cost of doubling its installed power capacity.

Figures 8 and 9 both considered the narrow band EFR service (service2), and similar results, with slightly larger $\Delta f_{\max }$ (around $0.01 \mathrm{~Hz}$ in average) were obtained for the wide band EFR service (service1) due to its wider dead-band, which slightly slows the BESS response.

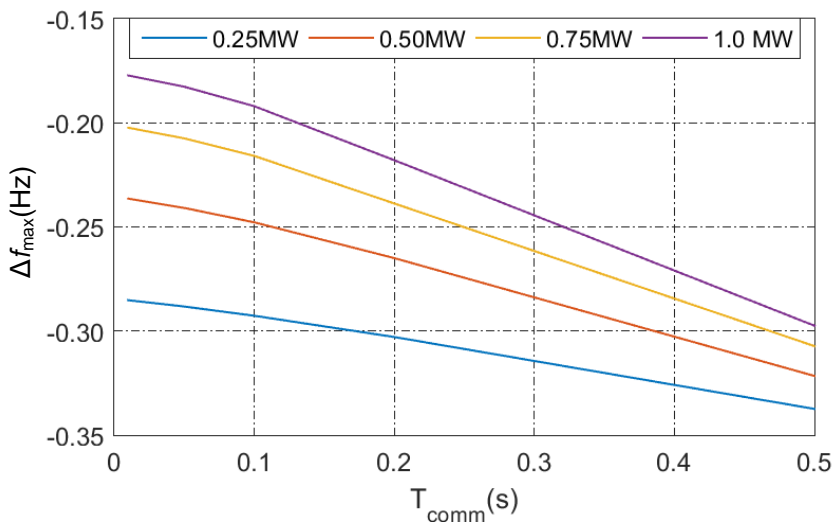

Figure 10: Impact of the BESS's power capacity $P_{B E S S}$ on the frequency nadir $\Delta f_{\max }$ in the EFR. $T_{d l v}=0.1 \mathrm{~s}$, narrow band EFR service 2 .

\section{HARDWARE-IN-THE-LOOP EXPERIMENTAL TESTS}

The SieStorage system is linked to the RTDS micro-grid model described in section III.A, forming a hardware-in-theloop testing system, as shown in Figure 11. HIL tests with the real SieStorage providing EFR services were carried out to validate the simulation studies. In the HIL test, the same $10 \%$ load-generation imbalance event is imposed on the RTDS micro-grid system. The frequency of the micro-grid system is measured and used with the EFR $P(f)$ curve to calculate the corresponding power reference value $P_{\text {ref }}$ in the RTDS. SieStorage executes the $P_{\text {ref }}$ command (in contrast to Section III which used an emulated BESS) and injects/ extracts $P_{\text {ref }}$ to/from the local LV grid. The output power measurement $P_{\text {mea }}$ of SieStorage is returned to the RTDS and used as the reference power of the dynamic AC source. The dynamic AC source then responds to the RTDS micro-grid system in exactly the same manner as the physical SieStorage system would actually respond to the LV grid for the same frequency event.

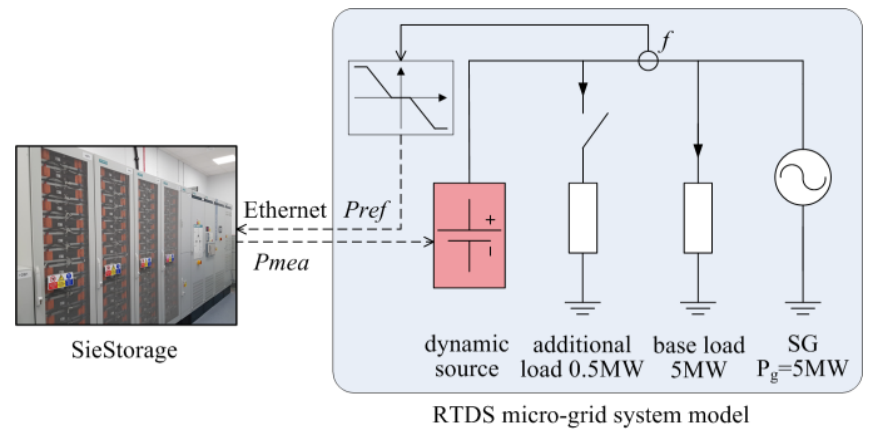

Figure 11: Diagram of the RTDS-SieStorage HIL test system. 
As the capacity of the micro-grid is an order of magnitude larger than that of the SieStorage system, a scale on $P_{\text {mea }}$ is applied. In the HIL experiments, two cases, with the $240 \mathrm{kVA}$ SieStorage system scaled up to a $0.5 \mathrm{MW}$ and a 1.0MW emulated BESS in the micro-grid model, are studied. The measurements and results are shown in Figure 12 and 13 , respectively.
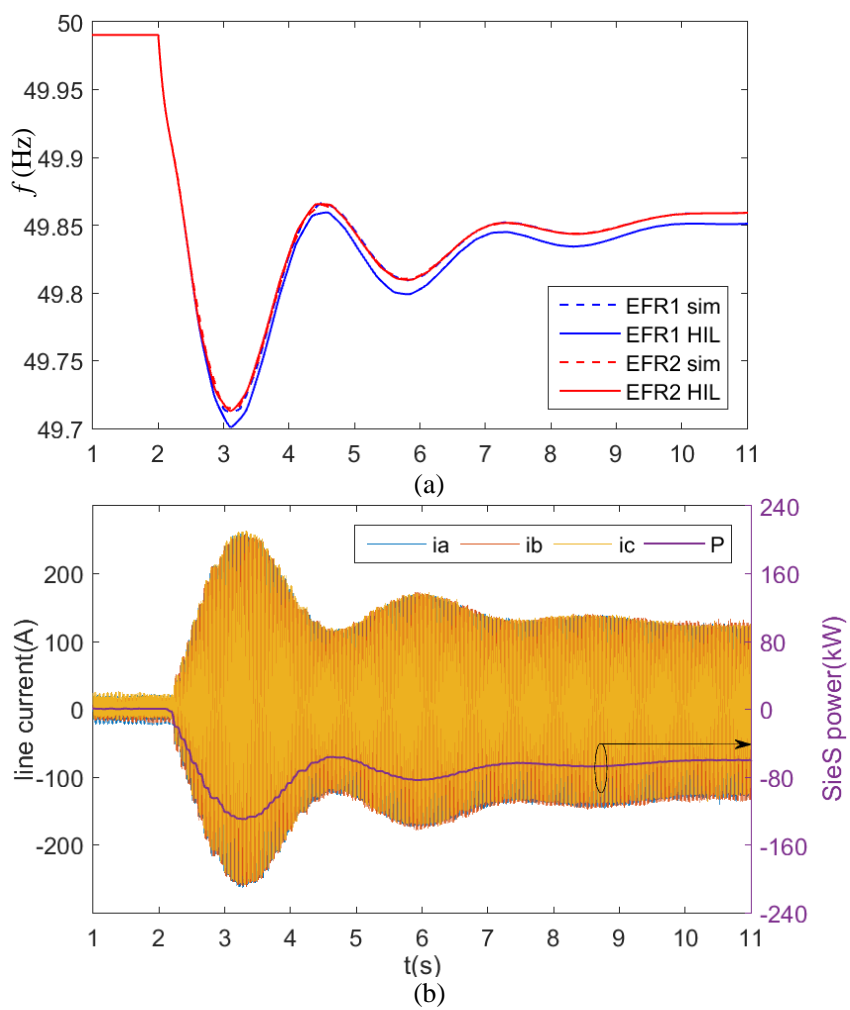

Figure 12. 0.5 MW HIL test results. (a) frequency transient in the simulation and HIL test, (b) measured power and line currents of SieStorage in the service 2 test case.
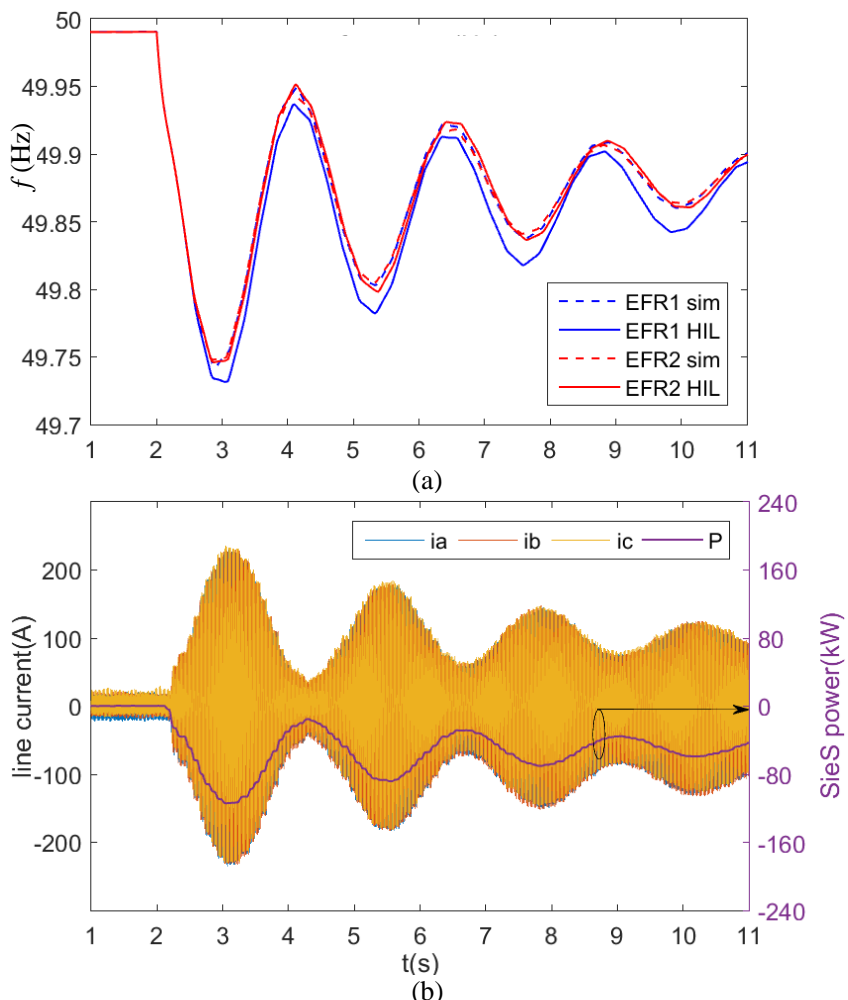

Figure 13. 1.0MW HIL test results. (a) frequency transient, (b) measured power and line currents of SieStorage.
For both EFR service1 and service2, and for both the $0.5 \mathrm{MW}$ scaling case and the $1.0 \mathrm{MW}$ scaling case, a consistent match (frequency difference less than $0.02 \mathrm{~Hz}$ ) between the measurements of the HIL tests and the RTDS simulation have been achieved, as shown in Figure 12(a) and Figure 13(a). In accordance with the findings in section III.B, the HIL tests also show the increased frequency oscillation and prolonged frequency settling time caused by the long communication latency (around $477 \mathrm{~ms}$ as identified in section II.C) of the SieStorage system. Also due to the long communication latency, the 1.0MW scaled BESS system just outperformed the $0.5 \mathrm{MW}$ scaled BESS by $0.03 \mathrm{~Hz}$. All the HIL test results match well with those from the simulation study.

\section{CONCLUSION}

The enhanced frequency response (EFR) services that the UK National Grid operator brought to market in 2016 are the latest frequency regulation products and also the most demanding ones on the response speed of the participating ESSs. This paper investigates the impacts of the response time of a BESS to its EFR performance. Comprehensive characterization of a $240 \mathrm{kVA} / 180 \mathrm{kWh}$ commercial BESS SieStorage is conducted, showing that it has an average response time of $0.162 \mathrm{~s}$, this includes a communication latency of around $90 \mathrm{~ms}$ from the remote controller to the storage site, and a physical delivery time of about $72 \mathrm{~ms}$. Based on the characterization results, SieStorage is then modelled within a representative micro-grid using RTDS. The impacts of the communication latency, the delivery time, the installed power capacity of the BESS, as well as the EFR service type is then investigated by simulation. Further, the commercial SieStorage system is linked to the representative micro-grid system forming a hardware-in-the-loop test platform. HIL tests on two different BESS power capacity cases for both the two types of EFR are conducted and the results are in high consistency with the simulation.

It is found in this study that the EFR performance of a BESS is greatly dependent on the communication latency, whereas the physical delivery time of the BESS power converters makes little difference if their delivery capability is less than $0.2 \mathrm{~s}$, which is not a particularly demanding requirement for modern power electronics. The findings indicate the importance of reducing the communication latency of EFR oriented BESSs. It also raises questions about how an aggregator should best combine assets with dissimilar characteristics to provide EFR services. It is also found that using a BESS to provide service2 EFR could achieve a slightly better frequency regulation than offering service1.

\section{REFERENCES}

[1] R. Hollinger, A. M. Cortes, and T. Erge, "Fast Frequency Response with BESS: A Comparative Analysis of Germany, Great Britain and Sweden," in 2018 15th International Conference on the European Energy Market (EEM), 2018, pp. 1-6.

[2] B. M. Gundogdu, S. Nejad, D. T. Gladwin, M. P. Foster, and D. A. Stone, "A Battery Energy Management Strategy for U.K. Enhanced Frequency Response and Triad Avoidance," IEEE Transactions on Industrial Electronics, vol. 65, pp. 9509-9517, 2018.

[3] N. grid, "Enhanced Frequency Response Market Information Report," Available: https://www.nationalgrideso.com/sites/eso/files/documents /EFR\%20Market\%20Information\%20Report\%20v1.pdf, 2016. 
[4] A. Adrees and J. V. Milanovic, "Study of frequency response in power system with renewable generation and energy storage," in 2016 Power Systems Computation Conference (PSCC), 2016, pp. 1-7.

[5] P. M. Ashton, C. S. Saunders, G. A. Taylor, A. M. Carter, and M. E. Bradley, "Inertia Estimation of the GB Power System Using Synchrophasor Measurements," IEEE Transactions on Power Systems, vol. 30, pp. 701-709, 2015.

[6] D. M. Greenwood, K. Y. Lim, C. Patsios, P. F. Lyons, Y. S. Lim, and P. C. Taylor, "Frequency response services designed for energy storage," Applied Energy, vol. 203, pp. 115-127, 2017/10/01/ 2017.

[7] S. Canevese, D. Cirio, A. Gatti, M. Rapizza, E. Micolano, and L. Pellegrino, "Simulation of enhanced frequency response by battery storage systems: The UK versus the continental europe system," in 2017 IEEE EEEIC / I\&CPS Europe, 2017, pp. 1-6.

[8] B. Gundogdu, D. T. Gladwin, and D. A. Stone, "Battery SOC management strategy for enhanced frequency response and day-ahead energy scheduling of BESS for energy arbitrage," in IECON 2017, pp. 7635-7640.

[9] T. Feehally, A. J. Forsyth, R. Todd, M. P. Foster, D. Gladwin, D. A Stone, et al., "Battery energy storage systems for the electricity grid: UK research facilities," in 8th IET PEMD 2016, 2016, pp. 1-6.

[10] J. Fang, Y. Tang, H. Li, and X. Li, "A Battery/Ultracapacitor Hybrid Energy Storage System for Implementing the Power Management of Virtual Synchronous Generators," IEEE Transactions on Power Electronics, vol. 33, pp. 2820-2824, 2018.

[11] nationalgridESO. (2019). Enhanced frequency response (EFR). Available: https://www.nationalgrideso.com/balancing-services/frequ -ency-response-services/enhanced-frequency-response-efr.

[12] M. Bahloul and S. K. Khadem, "Design and control of energy storage system for enhanced frequency response grid service," in 2018 IEEE ICIT, 2018, pp. 1189-1194.

[13] Alberto Bolzoni, Qingwei Zhu, Vasileios Tsormpatzoudis, Rebecca Todd, and Andrew Forsyth, "Dynamical Characterization of GridScale Energy Storage Assets," in IECON 2019, under review. 